\title{
EPDM の過酸化物加硫における老化防止剂の影響(8)
}

前回に, EPDM の過酸化物加硫において，表 1 に示 す当社の老化防止剂を使用した場合の加硫挙動( ムーニ ースコーチ試験, レオメータ試験) と加硫物引張物性試 験結果を示した，そして，加硫阻害の小さい老化防止剂 として, ノクラック MB, CD, AD, 224があげられ，特 にノクラック MB は $2 \mathrm{phr}$ 配合しても加硫挙動に及ぼす 悪影響はほとんど認められなかったことを紹介した。

今回は，これらの老化防止剂(表1)を配合した EPDM 過酸化物加硫ゴムの圧縮永久ひずみ試験(表 2) 及び熱老化試験結果(表 3)を紹介する.

圧縮永久ひずみは，加硫阻害の大きいノクラック 6C 配合加硫ゴムでは著しく悪くなるが，加硫阻害の小さい ノクラック MB, CD, AD, 224配合加硫ゴムでは良好で ある(表 2).

また，熱老化試験結果(表 3，図 1)から，ノクラック $\mathrm{MB}, \mathrm{CD}, \mathrm{AD}, 224, \mathrm{NBC}$ 配合加硫ゴムはいずれも耐熱 性の向上が認められ, 特にノクラック MB 配合加硫ゴ ムは耐熱性の著しい向上が認められる。

\section{実験}

配 合

$\mathrm{EPDM}^{*}$

ステアリン酸

100

酸化亜鉛

0.5

HAF ブラック

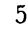

40

ジクミルパーオキサイド

老化防止鼡試料(表 1 に示す)（表 $2 \sim 3$ 中に示す）

*ヨウ素価19，ムーニー粘度 38, ENB 系

表 1 老化防止剤試料

\begin{tabular}{lll}
\hline 商品名 & (ノクラック $)$ 化 & \multicolumn{1}{c}{ 学 } \\
\hline CD & $\{4,4$ '-( $\alpha, \alpha$-Dimethyl benzyl $)$ diphenylamine $]$ \\
AD & Octylated diphenylamine \\
6C & N-Phenyl-N'-(1,3-dimethylbutyl $)$ - $p$-phenylenediamine \\
224 & Polymer of 2, 2, 4-trimethyl-1, 2-dihydroquinoline \\
MB & 2-Mercaptobenzimidazole \\
NBC & Nickel dibutyldithiocarbamate \\
\hline
\end{tabular}

( 85$)$

\section{5. 圧縮永久ひずみ試験}

JIS K·6301 に準拠

加硫物： $175^{\circ} \mathrm{C} ， 30$ 分プレス加硫物

表 2

\begin{tabular}{|c|c|c|c|c|}
\hline & \multirow{2}{*}{ 試 料 } & \multirow{2}{*}{$\begin{array}{c}\text { 配合量 } \\
\text { (phr) }\end{array}$} & \multicolumn{2}{|c|}{$\mathrm{CS}(\%), 150^{\circ} \mathrm{C}$} \\
\hline & & & $22 \mathrm{~h}$ & $70 \mathrm{~h}$ \\
\hline 1. & CD & $(0.5)$ & 12 & 18 \\
\hline 2. & CD & ( 1 ) & 16 & 22 \\
\hline 3. & AD & $(0.5)$ & 12 & 19 \\
\hline 4. & AD & ( 1 ) & 15 & 23 \\
\hline 5. & $6 \mathrm{C}$ & $(0.5)$ & 19 & 27 \\
\hline 6. & $6 \mathrm{C}$ & ( 1$)$ & 37 & 48 \\
\hline 7. & 224 & $(0.5)$ & 14 & 20 \\
\hline 8. & 224 & ( 1 ) & 17 & 25 \\
\hline 9. & MB & $(0.5)$ & 11 & 17 \\
\hline 10. & MB & ( 1 ) & 13 & 19 \\
\hline 11. & MB & $(2)$ & 16 & 23 \\
\hline 12. & NBC & $(0.5)$ & 15 & 22 \\
\hline 13. & NBC & (1) & 19 & 28 \\
\hline 14. & 無添加 & & 10 & 15 \\
\hline
\end{tabular}

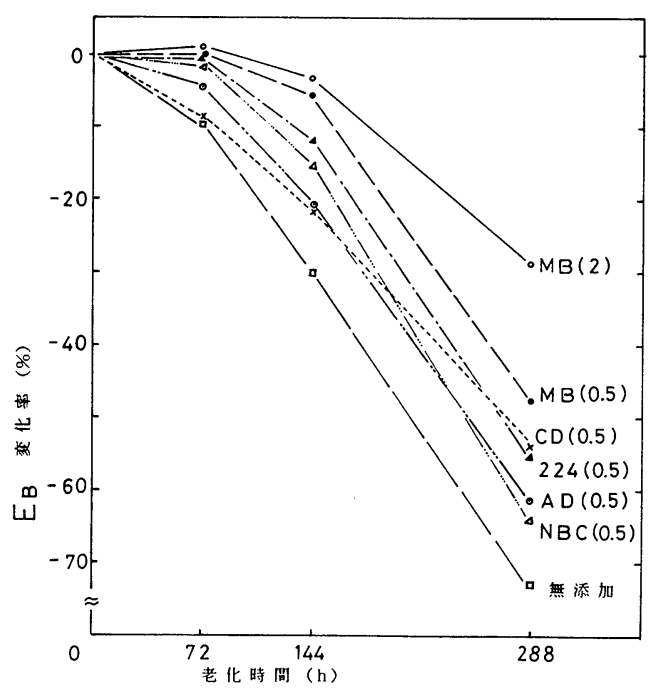

図 1 加硫物熱老化後の伸び $\left(\mathrm{E}_{\mathrm{B}}\right)$ 変化率 老化温度 $150^{\circ} \mathrm{C}$ 


\section{6. 熱老化試験}

JIS K 6301 に準拠，加硫物： $175^{\circ} \mathrm{C} ， 20$ 分プレス加硫

老化温度 : $150^{\circ} \mathrm{C}$ (試験管加熱老化試験)

表 3

\begin{tabular}{|c|c|c|c|c|c|c|c|}
\hline & 試 料 & $\begin{array}{l}\text { 配合量 } \\
\text { [phr] }\end{array}$ & $\begin{array}{c}\text { 老化時間 } \\
{[\mathrm{h}]}\end{array}$ & $\begin{array}{c}T_{\mathrm{B}} \\
{[\mathrm{MPa}]}\end{array}$ & $\begin{array}{c}E_{\mathrm{B}} \\
{[\%]}\end{array}$ & $\begin{array}{c}M_{100} \\
{[\mathrm{MPa}]}\end{array}$ & $\stackrel{H_{\mathrm{S}}}{[\mathrm{JIS} \mathrm{A}]}$ \\
\hline \multirow{3}{*}{1.} & \multirow{3}{*}{ CD } & \multirow{3}{*}[0.5]{} & 0 & 22.5 & 370 & 2.6 & 71 \\
\hline & & & 144 & $15.9(-29)$ & $290(-22)$ & $3.1(+19)$ & $75(+4)$ \\
\hline & & & 288 & $10.3(-54)$ & $170(-54)$ & $4.9(+88)$ & $78(+7)$ \\
\hline \multirow{3}{*}{2.} & \multirow{3}{*}{ CD } & \multirow{3}{*}[\begin{array}{l}{1}\\
{[}\end{array}]{} & 0 & 21.2 & 410 & 2.4 & 70 \\
\hline & & & 144 & $15.4(-27)$ & $300(-27)$ & $3.0(+25)$ & $75(+5)$ \\
\hline & & & 288 & $10.0(-53)$ & $160(-61)$ & $5.1(+113)$ & $78(+8)$ \\
\hline \multirow{3}{*}{3.} & \multirow{3}{*}{ AD } & \multirow{3}{*}[0.5]{} & 0 & 22.5 & 360 & 2.6 & 71 \\
\hline & & & 144 & $16.7(-26)$ & $280(-22)$ & $3.3(+27)$ & $75(+4)$ \\
\hline & & & 288 & $6.7(-70)$ & $120(-67)$ & $5.2(+100)$ & $78(+7)$ \\
\hline \multirow{3}{*}{4.} & \multirow{3}{*}{ AD } & \multirow{3}{*}[\begin{array}{l}{1}\end{array}]{} & 0 & 21.7 & 430 & 2.4 & 70 \\
\hline & & & 144 & $14.3(-34)$ & $290(-33)$ & $3.0(+25)$ & $75(+5)$ \\
\hline & & & 288 & $6.9(-68)$ & $130(-70)$ & $5.0(+108)$ & $79(+9)$ \\
\hline \multirow{3}{*}{5.} & \multirow{3}{*}{$6 \mathrm{C}$} & \multirow{3}{*}[0.5]{} & 0 & 20.9 & 460 & 2.3 & 70 \\
\hline & & & 144 & $17.2(-18)$ & $340(-26)$ & $2.9(+26)$ & $74(+4)$ \\
\hline & & & 288 & $8.8(-58)$ & $180(-61)$ & $4.2(+83)$ & $77(+7)$ \\
\hline \multirow{3}{*}{6.} & \multirow{3}{*}{$6 \mathrm{C}$} & \multirow{3}{*}[\begin{array}{l}{1}\end{array}]{} & 0 & 15.0 & 610 & 1.9 & 68 \\
\hline & & & 144 & $13.6(-9)$ & $360(-41)$ & $2.7(+42)$ & $74(+6)$ \\
\hline & & & 288 & $8.5(-43)$ & $190(-69)$ & $3.9(+105)$ & $77(+9)$ \\
\hline \multirow{3}{*}{7.} & \multirow{3}{*}{224} & \multirow{3}{*}[0.5]{} & 0 & 22.6 & 330 & 2.8 & 71 \\
\hline & & & 144 & $17.7(-22)$ & $290(-12)$ & $3.3(+18)$ & $75(+4)$ \\
\hline & & & 288 & $8.3(-63)$ & $150(-55)$ & $4.7(+68)$ & $78(+7)$ \\
\hline \multirow{3}{*}{8.} & \multirow{3}{*}{224} & \multirow{3}{*}[\begin{array}{l}{1}\\
{1}\end{array}]{} & 0 & 21.1 & 400 & 2.5 & 70 \\
\hline & & & 144 & $16.2(-23)$ & $290(-27)$ & $3.3(+32)$ & $76(+6)$ \\
\hline & & & 288 & $10.1(-52)$ & $170(-57)$ & $4.8(+72)$ & $78(+8)$ \\
\hline & & & 0 & 23.8 & 330 & 3.0 & 71 \\
\hline 9. & MB & {$[0.5]$} & 144 & $21.9(-8)$ & $310(-6)$ & $3.5(+17)$ & $76(+5)$ \\
\hline & & & 288 & $10.1(-58)$ & $170(-48)$ & $4.5(+50)$ & $78(+7)$ \\
\hline & & & 0 & 22.8 & 340 & 3.0 & 72 \\
\hline 10. & MB & {$\left[\begin{array}{l}1 \\
1\end{array}\right]$} & 144 & $22.1(-3)$ & $320(-6)$ & $3.6(+20)$ & $76(+4)$ \\
\hline & & & 288 & $13.9(-39)$ & $210(-38)$ & $4.6(+53)$ & $78(+6)$ \\
\hline & & & 0 & 23.0 & 340 & 3.0 & 72 \\
\hline 11. & MB & {$[2]$} & 144 & $22.1(-4)$ & $330(-3)$ & $3.7(+23)$ & $77(+5)$ \\
\hline & & & 288 & $17.4(-24)$ & $240(-29)$ & $4.9(+63)$ & $79(+7)$ \\
\hline & & & 0 & 22.5 & 400 & 2.5 & 69 \\
\hline 12. & NBC & {$[0.5]$} & 144 & $18.1(-20)$ & $340(-15)$ & $3.0(+20)$ & $74(+5)$ \\
\hline & & & 288 & $5.5(-76)$ & $100(-75)$ & - & $77(+8)$ \\
\hline & & & 0 & 21.9 & 470 & 2.3 & 69 \\
\hline 13. & NBC & {$\left[\begin{array}{l}1 \\
{[}\end{array}\right]$} & 144 & $18.5(-16)$ & $400(-15)$ & $2.7(+17)$ & $74(+5)$ \\
\hline & & & 288 & $7.6(-65)$ & $170(-64)$ & $4.2(+83)$ & $77(+8)$ \\
\hline & & & 0 & 21.4 & 300 & 3.2 & 71 \\
\hline 14. & 無添加 & & 144 & $15.1(-29)$ & $210(-30)$ & $4.3(+34)$ & $77(+6)$ \\
\hline & & & 288 & $5.5(-74)$ & $80(-73)$ & - & $80(+9)$ \\
\hline
\end{tabular}

$T_{\mathrm{B}}, E_{\mathrm{B}}, M_{100}$ の（）内は変化率（\%) を示す。 $H_{\mathrm{S}}$ の（）内は変化を示す。 